\title{
Measuring photosynthetic rates in seagrasses by pulse amplitude modulated (PAM) fluorometry
}

\author{
Sven Beer ${ }^{1, *}$, Boris Vilenkin ${ }^{1}$, Andreas Weil $^{1}$, Maik Veste $^{2}$, Laura Susel $^{1}$, Amram Eshel ${ }^{1}$ \\ ${ }^{1}$ Department of Plant Sciences, Tel Aviv University, Tel Aviv 69978, Israel \\ ${ }^{2}$ Department of Ecology, Bielefeld University, D-33501 Bielefeld, Germany
}

\begin{abstract}
Photosynthetic rates of seagrasses have until recently been measured as gas exchange of chamber-enclosed leaves mainly in the laboratory, and in situ measurements under natural conditions are scarce. In this work we explore the possibility of measuring such rates by pulse amplitude modulated (PAM) fluorometry, using a newly developed underwater device. This was done by first comparing photosynthetic $\mathrm{O}_{2}$ evolution (net photosynthesis corrected for dark respiration) with rates of electron transport (ETR) derived from fluorescence measurements of the effective quantum yield of photosystem Il multiplied with the estimated photon flux of photosynthetic active radiation absorbed by this photosystem. In the field, ETRs were then measured both as rapid light curves (RLCs) and by in situ point measurements under ambient light during the day. Photosynthetic $\mathrm{O}_{2}$ evolution showed a linear relationship with ETR within a range of irradiances for the Mediterranean seagrass Cymodocea nodosa, while the tropical Halophila stipulacea and a temperate intertidal population of Zostera marina exhibited decreasing $\mathrm{O}_{2}$ evolution rates relative to ETRs at high irradiances. These differences are likely due to photorespiration, which is absent in $\mathrm{C}$. nodosa. The molar ratio between photosynthetic $\mathrm{O}_{2}$ evolution and ETR within the range of their linear relationship was found to be 0.3 for C. nodosa, which is close to the theoretical stoichiometric ratio of 0.25 , but was higher and lower for $Z$. marina and $H$. stipulacea, respectively. Point measurements of ETR in the field showed good agreements with rates derived from RLCs for $H$. stipulacea and $Z$. marina, but values varied greatly between replicate measurements for $C$. nodosa at high irradiances. It is speculated that this variation was partly due to lightflecks caused by waves in the shallow water where these measurements were done. In all, this work shows that PAM fluorometry can efficiently yield photosynthetic rates for seagrasses in the laboratory, without the typical lag experienced by $\mathrm{O}_{2}$ electrodes, as well as in situ under natural conditions which are not disturbed by enclosures.
\end{abstract}

KEY WORDS: Marine angiosperms Photosynthesis - PAM fluorometry - Seagrasses

\section{INTRODUCTION}

Photosynthetic rates of marine angiosperms (seagrasses) are typically determined by enclosing the plants, or parts of them, in chambers and measuring either $\mathrm{O}_{2}$ evolution or ${ }^{14} \mathrm{CO}_{2} / \mathrm{H}^{14} \mathrm{CO}_{3}^{-}$uptake. While information on photosynthetic mechanisms has been obtained in this way (reviewed in Beer 1997), one drawback of this approach for eco-physiological studies is that the plants must either be removed from their growth site and/or be enclosed in chambers where

•E-mail: svenbeer@post.tau.ac.il conditions differ from those of their normal environment. Therefore, it has usually not been possible to determine rates of photosynthesis under in situ natural conditions for this plant group. Photosynthetic parameters can also be appraised by non-intrusive chlorophyll fluorescence measurements. For example, the potential (or maximal) quantum yield of electron flow through photosystem II (PSII) can be estimated in darkadapted plants as $F_{\mathrm{v}} / F_{\mathrm{m}}$ (Krause \& Weis 1991, see Dawson \& Dennison 1996 for the application of this method for seagrasses). In addition, pulse amplitude modulated (PAM) fluorometry has made it possible to determine a similar parameter also in the light as $\Delta F / F_{\mathrm{m}}{ }^{\prime}$, where $F_{\mathrm{m}}{ }^{\prime}$ is the maximal fluorescence of a light- 
adapted plant when all reaction centres are reduced, or closed (as caused by a short dose of saturating light), and $\Delta F=F_{\mathrm{m}}{ }^{\prime}-F$, $F$ being the fluorescence in the light when part of the reaction centres are open (see Schreiber \& Bilger 1993). $F / F_{\mathrm{m}}$ 'can be termed the effective quantum yield $(Y)$ of photosynthetic electron transport through PSII, and this parameter has been shown to vary proportionally with the quantum yield as determined either by $\mathrm{CO}_{2}$ uptake in barley (Genty et al. 1989) or, within a certain range of irradiances, $\mathrm{O}_{2}$ evolution in a cyano-lichen (Sundberg et al. 1997). If so, then multiplying $Y$ by the photosynthetic photon flux (PPF) absorbed by PSII (in $\mu$ mol photons $\mathrm{m}^{-2} \mathrm{~s}^{-1}$ ) should yield rates of photosynthetic electron transport (ETR, in $\mu \mathrm{mol}$ electrons $\mathrm{m}^{-2} \mathrm{~s}^{-1}$ ). While PAM fluorometers thus can determine $Y$, quantitative calculations of ETR require that at least the fraction of PPF absorbed by the leaf (AF) is known so that the irradiance absorbed by PSII can be estimated.

The first underwater PAM fluorometer became commercially available in April 1997. Since then, a few reports have evaluated its use for measuring relative (Schreiber et al. 1997, Beer \& Ilan 1998, Ralph pers. comm.) as well as absolute (Beer et al. 1998) photosynthetic rates of photosymbiont-containing marine invertebrates. In one as yet unpublished study by Beer \& Björk, the photosynthetic performance of 2 tropical intertidal seagrasses was measured by PAM fluorometry. When comparing ETRs as a function of PPF with rates of $\mathrm{O}_{2}$ evolution, a linear relationship was found for one of the species (Halophila ovalis) but not for the other (Halodule wrightii); in the latter, rates of $\mathrm{O}_{2}$ evolution became lower relative to ETRs at high PPFs. These differences, as well as the scarcity of similar data, urged us to verify the use of PAM fluorometry for quantitative photosynthetic assessments in a wider variety of seagrasses including, for the first time, in situ underwater measurements. This was done by (1) estimating their AF values, (2) comparing the light responses of ETR with those of $\mathrm{O}_{2}$ evolution and (3) performing field measurements in situ, both as rapid light curves (RLCs) and as point measurements under ambient light.

\section{MATERIALS AND METHODS}

Plant material. Three seagrass species were used in this study. One of them, an eastern Mediterranean population of Cymodocea nodosa (Ucria) Aschers., was found growing in shallow water outside the Limnological and Oceanographic Institute, Haifa, Israel $\left(32^{\circ}\right.$ $50^{\prime} \mathrm{N}, 34^{\circ} 57^{\prime} \mathrm{E}$ ). While laboratory $\mathrm{O}_{2}$ exchange versus fluorometric measurements were done at the institute, field fluorometry was carried out in situ at ca $0.5 \mathrm{~m}$ depth (in November 1997). A second species investigated was Halophila stipulacea (Forssk.) Aschers. from the northwestern coast of the Gulf of Aqaba, the Red Sea. Laboratory experiments were carried out at the Inter-University Institute in Eilat, Israel $\left(31^{\circ} 35^{\prime} \mathrm{N}, 34^{\circ}\right.$ $54^{\prime} \mathrm{E}$ ), and field measurements were done at ca $6 \mathrm{~m}$ depth just outside the institute (in October 1997). The third seagrass used was an intertidal population of the temperate Zostera marina L. from the White Sea, northwestern Russia. Laboratory measurements were done at the Kartesh Zoological Station east of Chupa, some $40 \mathrm{~km}$ south of the polar circle $\left(66^{\circ} 20^{\prime} \mathrm{N}, 33^{\circ}\right.$ $40^{\prime} \mathrm{E}$ ), while field work was carried out on air-exposed plants during low tide in a nearby bay (in late September 1997).

Determining fractions of absorbed light (AF). AF values of the different seagrasses were determined in the following way: leaves were placed on top of photosynthetic active radiation (PAR) quantum sensors connected either to a Li-Cor (USA) LI-189 (for Zostera marina in the air), or to the light meter of the fluorometer described below (for the other 2 species during submersion). The irradiance from a fibre-guided halogen light source (Schott, Germany) reaching the sensors $(L r)$ through 1 to 4 layers of leaves was recorded. The $\ln (L r)$ values were then plotted against the number of leaf layers, and the linear correlation was calculated. The slope of this line $(\alpha)$ and the $y$-intercept $(I)$ were determined by regression analysis, and AF was calculated as $1-\exp (-\alpha)$. Reflectance from the upper leaf surfaces was estimated as the difference between the irradiance extrapolated to zero leaves [exp $(I)]$ and the incident irradiance actually measured when no leaves were present. No significant difference could be found between these 2 values in these seagrasses, and it was assumed that the AF values obtained therefore adequately described the fraction of light absorbed by the leaves.

Comparing $\mathrm{O}_{2}$ evolution and electron transport. 'Gross' photosynthetic $\mathrm{O}_{2}$ evolution rates (net photosynthesis corrected for dark respiration) were determined for ca $3 \mathrm{~cm}$ long leaf sections (or whole Ieaves for Halophila stipulaced) using a Hansatech (UK) $\mathrm{O}_{2}$ electrode set-up. The leaves were inserted into the electrode chamber in the shape of an upside-down ' $U$ '. Light, at various irradiances, was supplied by a dualfibre optically guided halogen lamp (Schott, Germany) in a way that provided a seemingly uniform distribution along both sides of the leaf. Temperatures during these measurements were kept close to the ambient ones: $20^{\circ} \mathrm{C}$ for Cymodocea nodosa, $23^{\circ} \mathrm{C}$ for $H$. stipulacea and $7^{\circ} \mathrm{C}$ for Zostera marina.

Simultaneous to the $\mathrm{O}_{2}$ measurements, chlorophyll fluorescence parameters were measured using the PAM fluorometer Diving-PAM (Walz GmbH, Ger- 
many). This was done by inserting the tip of the instrument's main optical fibre into the $\mathrm{O}_{2}$ electrode chamber so that it closed the chamber and rested ca $5 \mathrm{~mm}$ away from the upper bent part of the ' $\mathrm{U}$ '-shaped leaf. The internal clock of the fluorometer was set to measure $Y\left[=\left(F_{\mathrm{m}}{ }^{\prime}-F\right) / F_{m}{ }^{\prime}\right]$ at regular intervals, and ETR was calculated as $Y \cdot$ incident PAR $\cdot \mathrm{AF} \cdot 0.5$ (assuming that all light absorbed by the leaf was absorbed by chlorophyll, and that both photosystems absorbed equal amounts of the incoming photons).

Field fluorometry. Field measurements with the Diving-PAM were done both on air-exposed (Zostera marina) and submerged shallow (Cymodocea nodosa, in choppy waters, by snorkelling), as well as deeper (Halophila stipulacea accessed by SCUBA diving) growing, plants. Rapid (within 5 min) light response curves (RLCs) were generated by irradiating parts of leaves with the actinic (photosynthesis-causing) light source of the Diving-PAM at pre-set PPFs. This was done by clipping part of an intact leaf to a modified 'dark leaf clip' with the shutter open, and then attaching the tip of the instrument's main light guide to it just before starting a RLC. (The clip was modified so as to allow for water flow around the leaf segment measured through small drilled holes.) Values of ETR were calculated as described above. Since the leaf clip used could not accommodate the PAR sensor of the Diving-PAM, the incident PPF values were measured separately for the same settings of the actinic light source by clipping the tip of the instrument's light-guided quantum sensor (instead of the leaf) to the 'dark leaf clip'. Various exposure times to the actinic light showed that optimal ETR values for all 3 seagrasses could be reached within 30 to $40 \mathrm{~s}$ irradiation at each light level, and the latter time was set as the instrument's so-called 'actinic width' for all subsequent RLC measurements.

In addition to the light response curves, point measurements under natural light were carried out on 20 to 30 different leaves in the 3 different seagrass beds at various times of day. The 'leaf distance clip' was used for this purpose, and the tip of the Diving-PAM's PAR sensor was also attached to this clip so that it recorded the incident irradiance adjacent to the leaf, and at the same angle of downwelling light as experienced by the leaf, at the time of each separate measurement. Values of ETR were either calculated as described above after downloading the measured data from the Diving-PAM's memory to a computer, or were calculated by the Diving-PAM itself in cases where the correct AF had been pre-programmed into the Diving-PAM's memory point termed 'ETR factor' (instead of the pre-set value of 0.84 ).

\section{RESULTS}

Values of AF for the different seagrass leaves are shown in Table 1 . These values were all lower than the default 'ETR factor' of 0.84 set for the Diving-PAM, and they were used when calculating ETRs. The differences in AF values among the species are mostly due to different thicknesses and chlorophyll contents of the leaves.

A time course of $\mathrm{O}_{2}$ evolution and simultaneous ETR measurements for Cymodocea nodosa is depicted in Fig. 1a. During this time course, the irradiance was varied stepwise, and $\mathrm{O}_{2}$ evolution generally followed the ETR. However, a noticeable difference between
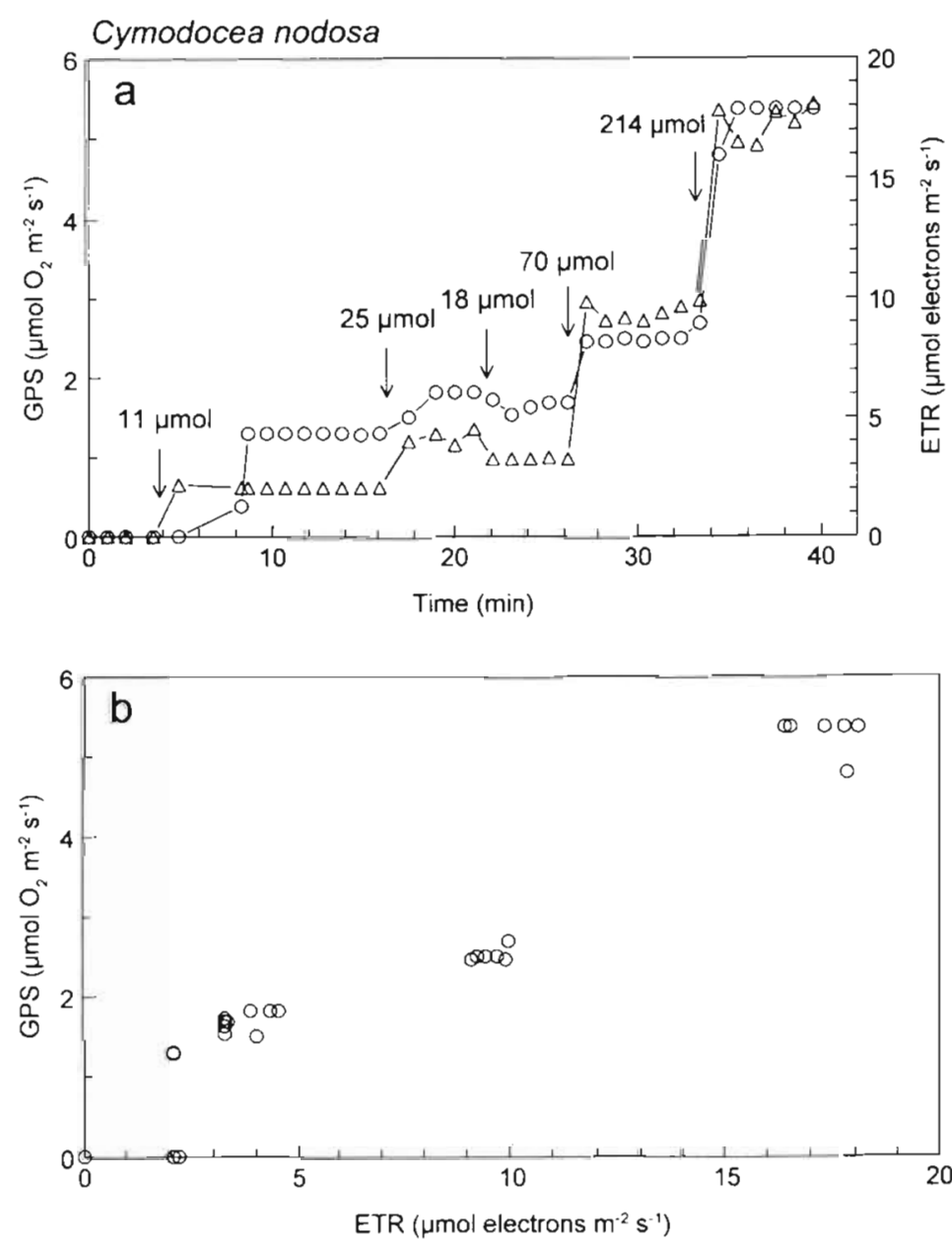

Fig. 1. (a) Time course of photosynthetic $\mathrm{O}_{2}$ evolution (GPS, $\mathrm{O}$, left $y$-axis) and electron transport rate (ETR, $\triangle$, right $y$-axis) at various irradiances (indicated as $\mu \mathrm{mol}$ photons $\mathrm{m}^{-2} \mathrm{~s}^{-1}$ ) and (b) the corresponding GPS versus $\mathrm{ETR}$, in a leaf of Cymodocea nodosa. Measurements were done at $20^{\circ} \mathrm{C}$ 


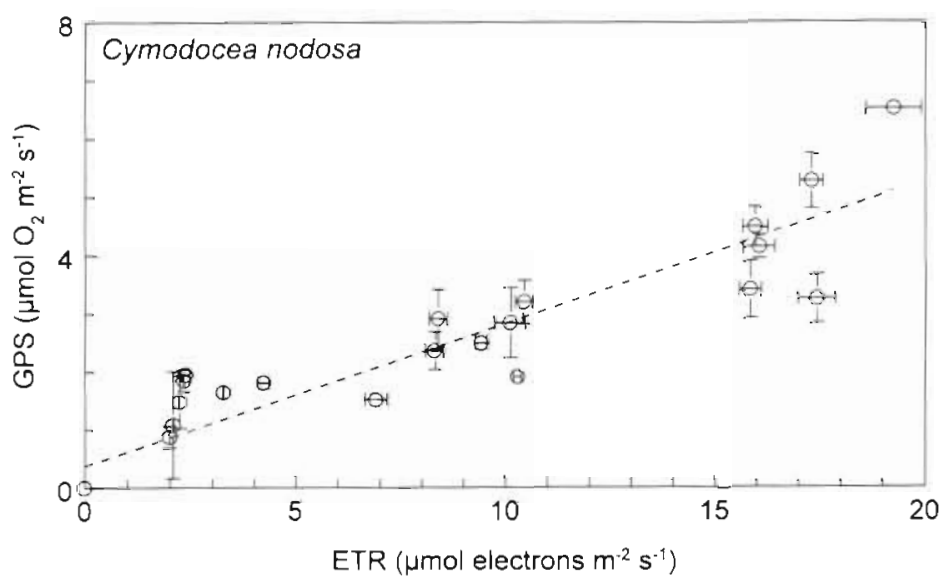

Fig. 2. Average rates of photosynthetic $\mathrm{O}_{2}$ evolution (GPS) versus electron transport (ETR) in leaves of Cymodocea nodosa (measured at $20^{\circ} \mathrm{C}$ ). Data points are average of 3 to 6 measurements \pm SE for each of 4 leaves at various irradiances $\left(0\right.$ to $300 \mu$ mol photons $\mathrm{m}^{-2} \mathrm{~s}^{-1}$, increasing toward the right in the figure). The points were fitted to a straight line, $\mathrm{r}^{2}=0.93$
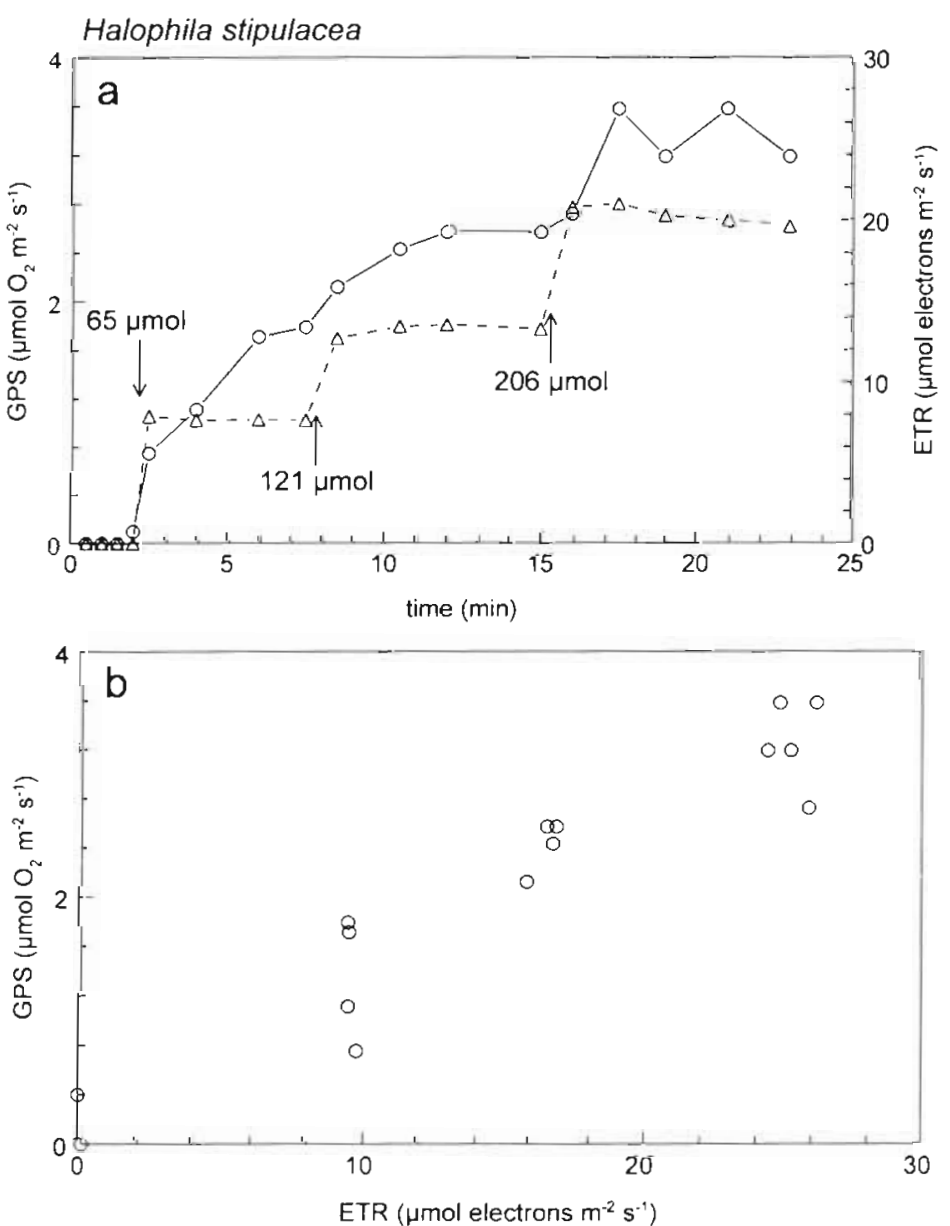

Fig. 3. (a) Time course of photosynthetic $\mathrm{O}_{2}$ evolution (GPS, $\mathrm{O}$, left $y$-axis) and electron transport rate (ETR, $\triangle$, right $y$-axis) at various irradiances (indicated as $\mu \mathrm{mol}$ photons $\mathrm{m}^{-2} \mathrm{~s}{ }^{1}$ ) and (b) the corresponding GPS versus ETR, in a leaf of Halophila stipulacea. Measurements were done at $23^{\circ} \mathrm{C}$
Table 1. Average $( \pm S D, n=5$ ) fractions of incident light absorbed by a leaf (AF) of the different seagrasses

\begin{tabular}{|lc|}
\hline Species & $\mathrm{AF}$ \\
\hline Cymodocea nodosa & $0.72 \pm 0.11$ \\
Halophila stipulacea & $0.50 \pm 0.03$ \\
Zostera marina & $0.44 \pm 0.02$ \\
\hline
\end{tabular}

the 2 measurements was the lag of a few minutes for obtaining steady-state $\mathrm{O}_{2}$ evolution rates following each alteration of the irradiance, while the ETRs showed immediate responses. Plotting the $\mathrm{O}_{2}$ data versus ETRs (Fig. 1b) showed a linear relationship between these 2 parameters. Similarly, the average photosynthetic rates recorded at steady-state $\mathrm{O}_{2}$ evolution varied linearly $\left(\mathrm{r}^{2}=0.93\right)$ with average values of ETR for 4 different leaves under different irradiance levels up to $300 \mu \mathrm{mol}$ photons $\mathrm{m}^{-2} \mathrm{~s}^{-1}$ (Fig. 2). The coefficients of variation were higher for the $\mathrm{O}_{2}$ than for the ETR data. The molar ratio of ETR and $\mathrm{O}_{2}$ evolution was ca 0.3 , which is close to the theoretical value of 0.25 (4 mol electrons $\mathrm{mol}^{-1} \mathrm{O}_{2}$ evolved in photosynthesis).

Time courses of $\mathrm{O}_{2}$ evolution and ETRs, and the corresponding relationships between the 2 measurements, for Halophila stipulacea (Fig. 3) and Zostera marina (Fig. 4) show trends similar to those found for Cymodoca nodosa in that a lag was present in the response time of the $\mathrm{O}_{2}$ measurements, while more stable fluorescence-based ETR values were obtained immediately upon changing the irradiance level. However, unlike the linear relationship observed for $C$. nodosa, $H$. stipulacea (Fig. 5) and, especially, Z. marina (Fig. 6) showed reduced rates of steady-state $\mathrm{O}_{2}$ evolution relative to ETRs at high irradiances (toward the right in the figures). Also here, the coefficient of variation was lower for the ETRs than for the $\mathrm{O}_{2}$ evolution. Within the linear range of these relationships (i.e. at low light), the molar ratio of ETRs to rates of photosynthetic $\mathrm{O}_{2}$ evolution was 0.12 for $H$. stipulacea and 0.5 for $Z$. marina

Photosynthetic ETR responses to irradiance derived from the actinic halogen light source of the Diving-PAM (i.e. the RLCs) measured in the field during midday yielded apparently typical photosynthesis-irradiance relationships for all 3 species (Figs. 7-9). The results of in situ point measurements under natural 
light, superimposed on the RLCs, show that average ETRs measured between 09:00 and 13:30 $\mathrm{h}$, and thus under various ambient light conditions, agreed well with these curves. There was, however, a large variation between the measurements at high light for Cymodocea nodosa (Fig. 7) as reflected by the high standard deviations of the mean values. Plotting the individual measurements revealed that there was no correlation between the single ETR values and the irradiance at which each of them had been measured. On the other hand, no such spread of the individual measurements was found a little earlier in the day when the irradiance was $<100 \mu \mathrm{mol}$ photons $\mathrm{m}^{-2} \mathrm{~s}^{-1}$ due to clouds. For this seagrass, which grew at relatively high midday irradiances, light saturation occurred at ca $600 \mu \mathrm{mol}$ photons $\mathrm{m}^{-2} \mathrm{~s}^{-1}$ and the maximal photosynthetic ETRs were high. Halophila stipulacea growing under much dimmer light at $6 \mathrm{~m}$ depth (Fig. 8) showed close to saturating ETRs at ca $250 \mu \mathrm{mol}$ photons $\mathrm{m}^{-2} \mathrm{~s}^{-1}$, but rates continued to increase slightly at higher irradiances. A low light saturation point of $\mathrm{ca}$ $150 \mu \mathrm{mol}$ photons $\mathrm{m}^{-2} \mathrm{~s}^{-1}$, and rates decreasing at higher irradiances, was found for the temperate Zostera marina (Fig. 9) investigated under a low-light season.

\section{DISCUSSION}

Direct linear or curvilinear relationships between photosynthetic rates as measured with the $\mathrm{O}_{2}$ electrode and those measured as ETRs with the Diving-PAM were found for all 3 species investigated. A linear correlation was found for Cymodocea nodosa, a seagrass which has previously been shown to possess a $\mathrm{C}_{4}$-like $\mathrm{CO}_{2}$ incorporation pattern (Beer \& Waisel 1979), and which lacks apparent photorespiration as appraised by its $\mathrm{O}_{2}$-insensitive photosynthetic rates (cf. Beer 1989). Contrary to this, rates of $\mathrm{O}_{2}$ evolution decreased relative to ETRs in the high rate range for the other 2 species. While all rates of $\mathrm{O}_{2}$ evolution were calculated as 'gross' rates by correcting for dark respiration from the measured rates of net $\mathrm{O}_{2}$ exchange, photorespiration could not be accounted for here. As the relative decrease in $\mathrm{O}_{2}$ evolution occurred at high irradiances, and since no such decrease was found for the species lacking apparent photorespiration, it seems very likely that photorespiration was
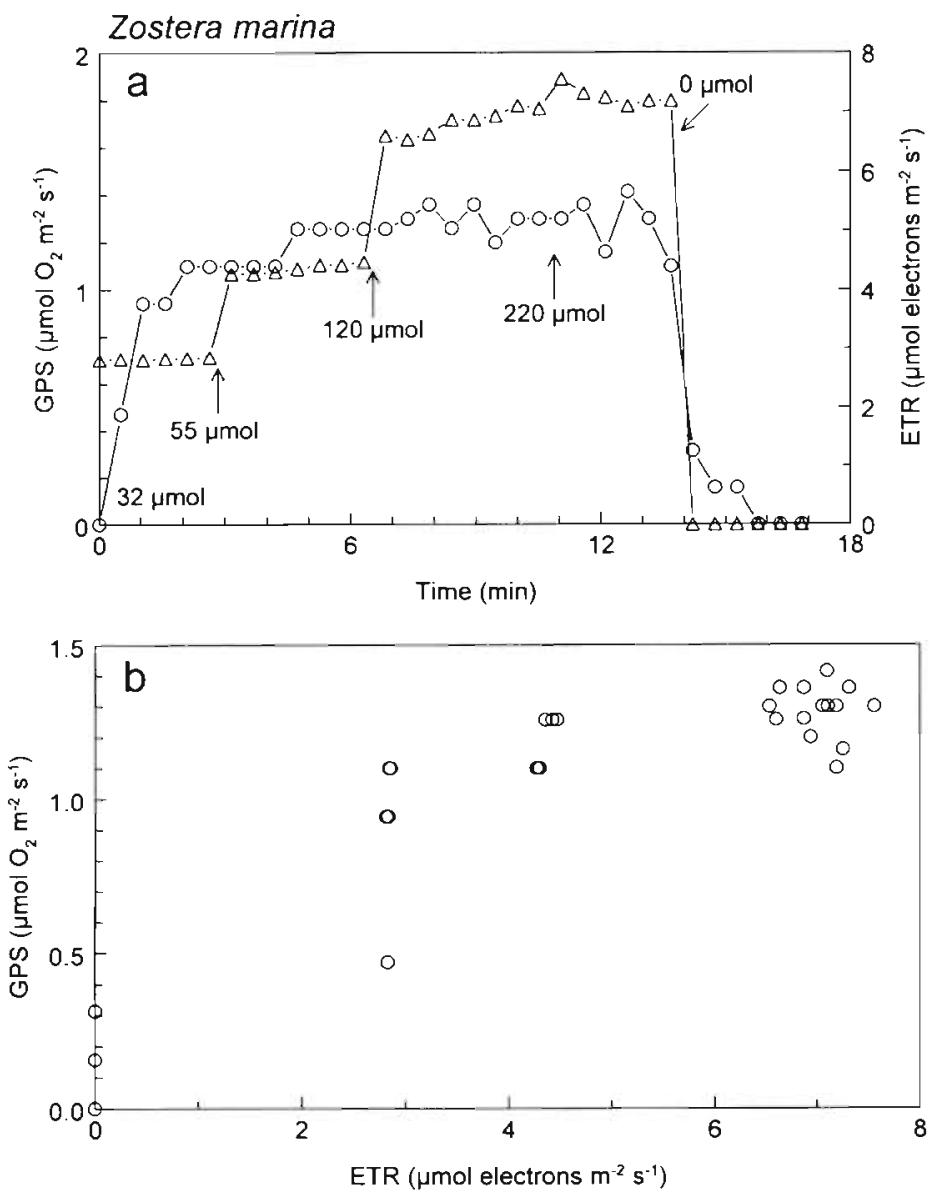

Fig. 4. (a) Time course of photosynthetic $\mathrm{O}_{2}$ evolution (GPS, $\mathrm{O}$ left $y$-axis) and electron transport rate (ETR, $\triangle$, right $y$-axis) at various irradiances (indicated as $\mu \mathrm{mol}$ photons $\mathrm{m}^{-2} \mathrm{~s}^{-1}$ ) and (b) the corresponding GPS versus ETR, in a leaf of Zostera marina. Measurements were done at $7^{\circ} \mathrm{C}$

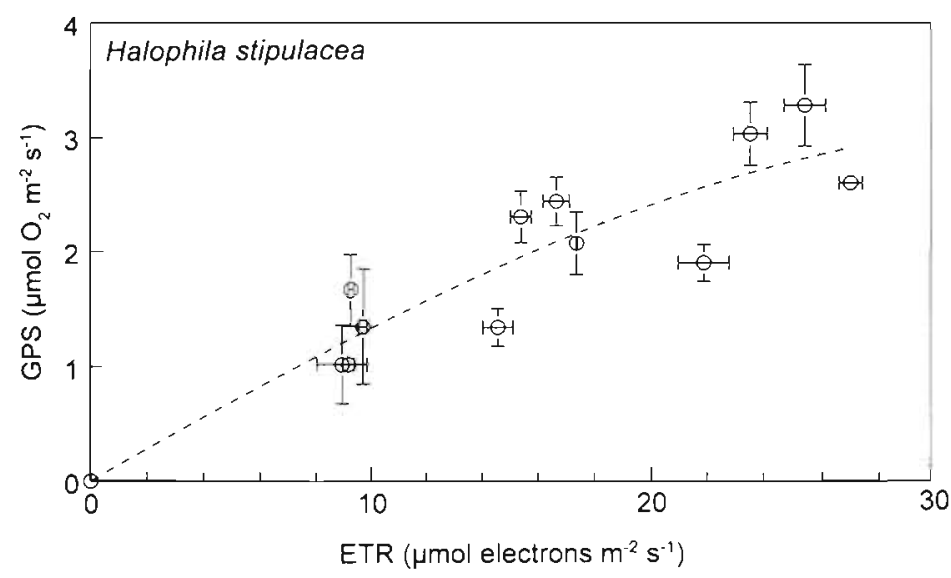

Fig. 5. Average rates of photosynthetic $\mathrm{O}_{2}$ evolution (GPS) versus electron transport (ETR) in leaves of Halophila stipulaced (measured at $23^{\circ} \mathrm{C}$ ). Data points are average of 3 to 6 measurements \pm SE for each of 4 leaves at various irradiances $\left(0\right.$ to $250 \mu \mathrm{mol}$ photons $\mathrm{m}^{-2} \mathrm{~s}^{-1}$, increasing toward the right in the figure). The points were fitted to a third degree polynomial function, $\mathrm{r}^{2}=0.95$ 


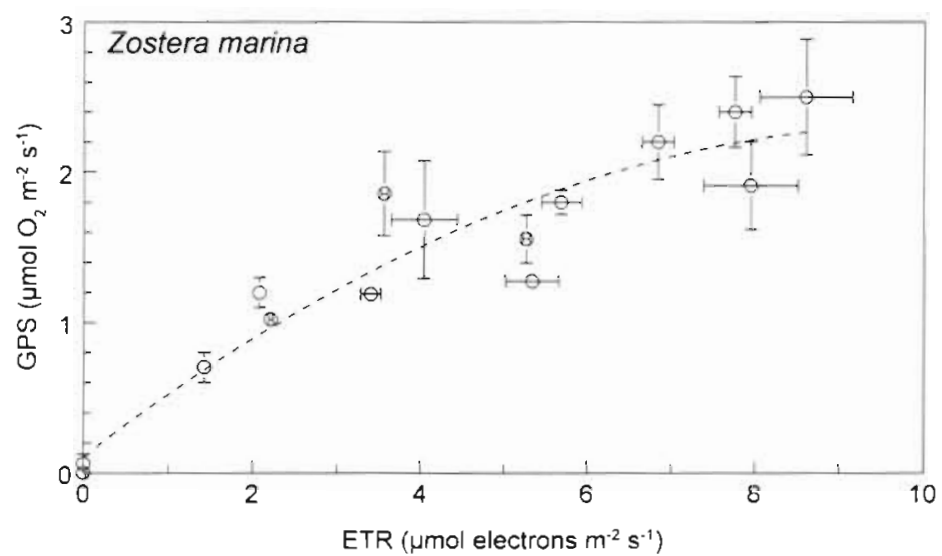

Fig. 6. Average rates of photosynthetic $\mathrm{O}_{2}$ evolution (GPS) versus electron transport (ETR) in leaves of Zostera marina (measured at $7^{\circ} \mathrm{C}$ ). Data points are average of 3 to 10 measurements \pm SE for each of 4 leaves at various irradiances $\left(0\right.$ to $250 \mu \mathrm{mol}$ photons $\mathrm{m}^{-2} \mathrm{~s}^{-1}$, increasing toward the right in the figure). The points were fitted to a second degree polynomial function, $\mathrm{r}^{2}=0.95$

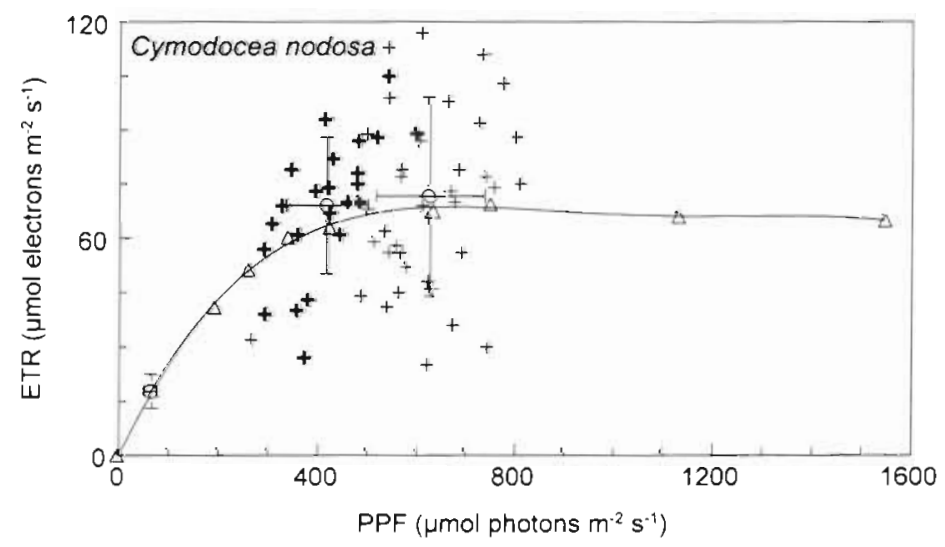

Fig. 7 Rapid light curve of photosynthetic electron transport rates (ETR) versus incident photosynthetic photon flux (PPF) measured in the field at noon-time $(\Delta)$, and average $(n=20$ to 35$)$ in situ point measurements of ETR under ambient light $(0), \pm S D$, taken at (from left to right) 10:15, 12:00 and 13:00 h, for a Cymodocea nodosa population growing at $0.5 \mathrm{~m}$ depth at a temperature of $20^{\circ} \mathrm{C}$. Each point measurement is also given for 12:00 (+) and 13:00 $\mathrm{h} \mathrm{(+)}$

the cause of the deviation from linearity for Halophila stipulacea and C. nodosa.

A comparison of photosynthetic rates measured by the $\mathrm{O}_{2}$ electrode and those calculated from the fluorescence data showed a close to theoretical stoichiometric relationship of 0.25 (4 mol electrons $\mathrm{mol}^{-1} \mathrm{O}_{2}$ evolved) for Cymodoca nodosa, while both higher and lower values were obtained for the other species at low irradiances (where photorespiration was minimised). A potential cause for the latter deviations may be experimental in that it is hard to supply exactly the same PPF for the part of the leaf where fluorescence was measured as for the overall leaf within the $\mathrm{O}_{2}$ electrode chamber. A potentially contributing biological cause for the deviations from the expected quantitative relationship between $\mathrm{O}_{2}$ evolution and ETR may be that the modulated measuring light was intercepted differently from the incident actinic light throughout the leaf cross sections. Also, it must be realised that not all light absorbed by the leaf pigments is used in the photochemical reactions, and that light interception can vary depending on chloroplast locations within the cells at various irradiances (see below). Thus, the AF values used here for determining ETRs quantitatively should be seen as a first approach only, and more exact ways to determine the AF values than the one used here may be sought. If this is not possible, then E'TR values can be given as relative ones (by simply multiplying $Y$ with the incident PPR). Since the average molar $\mathrm{O}_{2} / \mathrm{ETR}$ ratio among the 3 species was close to the theoretical one, and since there is no other apparent rationale for the varying $\mathrm{O}_{2}$ /ETR ratios among the species, it is however suggested that the deviations from 0.25 were mainly due to inexact irradiance determinations; this would affect the values of ETR directly since PPF is a multiplicand in calculating them. In all, it is concluded that the Diving-PAM is suitable for measurements of photosynthetic ETRs in seagrasses provided that the incident PPF can be measured exactly, and the latter is easier to do in the field than within the $\mathrm{O}_{2}$ chambers.

When testing the Diving-PAM in the field, the RLCs of ETR versus PPF yielded apparently typical photosynthesis-irradiance responses by irradiating the leaves for 30 to $40 \mathrm{~s}$ at each light level. Thus, such RLCs could be generated within minutes. One point of concern in the RLCs is that the internal light source of the Diving-PAM is a halogen lamp and, therefore, that the spectrum of the PPF changes at various intensity settings (shifting toward red as the PPF is decreased). The decrease in rates at high irradiances for Zostera marina may be due to down-regulation of photosynthesis in this plant which grew at low ambient irradiances. On the other hand, the increasing rates in Halophila stipulacea at $>250 \mu \mathrm{mol}$ photons $\mathrm{m}^{-2} \mathrm{~s}^{-1}$ may be due to cellular adaptations; it has been shown that the chloroplasts of this species can change their position within the cells so as to apparently optimise light interception at low irradiances and minimise photoinhibition in high light (Drew 1978). In situ point measurements within a limited number of hours during the day showed average values fitting those estimated for the same irradiance from the midday RLCs. The high scat- 
ter between repetitive measurements in $C y$ modocea nodosa at 13:00 h was not due to variations in PPF at each individual measurement and, therefore, probably partly reflects average physiological responses to the sunlight flickering which was visibly caused by the choppy water surface. Such effects have been reported before for both terrestrial plants (Pearcy 1990) and algae. For the latter, it was shown that light flecks could enhance (Wing \& Patterson 1993) or reduce (Kubler \& Raven 1996) photosynthetic rates as compared to those at steady light. On the other hand, no such scatter was observed earlier under a cloud cover or at lower irradiances for the other plants.

Based on the results of the above trials, it is concluded that PAM fluorometry is suitable for determining photosynthetic rates of seagrasses both in the laboratory and in situ. The Diving-PAM further allows for such measurements to be done underwater to depths of $50 \mathrm{~m}$. Because PAM fluorometry measures only photon-driven electron transport (which gives rise to $\mathrm{O}_{2}$ evolution, but also to photorespiration and other possible $\mathrm{O}_{2}$-consuming reactions involving electron flow through PSII), it cannot be applied by itself if energy or gas exchange budgets are to be determined since these depend also on diurnal rates of dark respiration. It can, however, be used in experiments where responses of the photosynthetic system per se are sought. This is exemplified in the low light saturation point and maximal ETR of Zostera marina growing at low irradiances and a low temperature as compared to the subtropical Cymodocea nodosa growing in well-lit warmer waters. In continuation of an eco-physiological study of tropical seagrasses (Björk et al. 1997), we have also used the method for determining photosynthetic responses of intertidal seagrasses to desiccation and re-submersion (Björk \& Beer unpubl.).

Acknowledgements. We thank Jonathan Beer for his help in SCUBA diving, and Robert Weil, Sweden, for generously supporting this research. Thanks are also due to the staff of the Kartesh Zoological Station, Russia, and especially to Yuri Nikolaevich Kurzikov for his technical support.

\section{LITERATURE CITED}

Beer S (1989) Photosynthesis and photorespiration in marine angiosperms. Aquat Bot 34:153-166

Beer S (1997) Inorganic carbon transport in seagrasses. In: Kuo J, Walker DI, Kirkman H (eds) Seagrass biology,

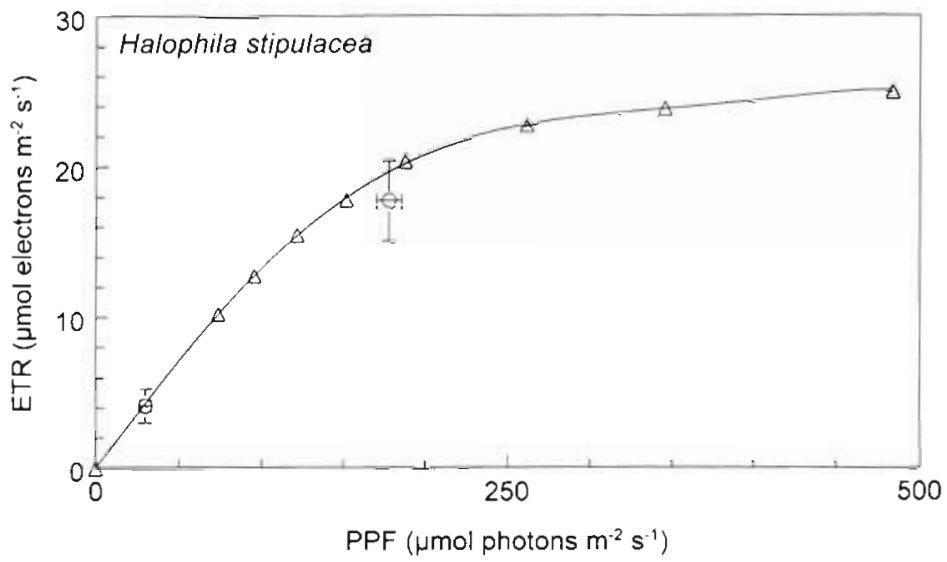

Fig. 8. Rapid light curve of photosynthetic electron transport rates (ETR) versus incident photosynthetic photon flux (PPF) measured at noon-time $(\Delta)$, and average $(\mathrm{n}=20$ to 30 ) in situ point measurements of ETR under ambient light $(0), \pm S D$, taken at (from left to right) 09:15 and 13:00 h, for a Halophila stipulacea population growing at $6 \mathrm{~m}$ depth at a temperature of $23^{\circ} \mathrm{C}$

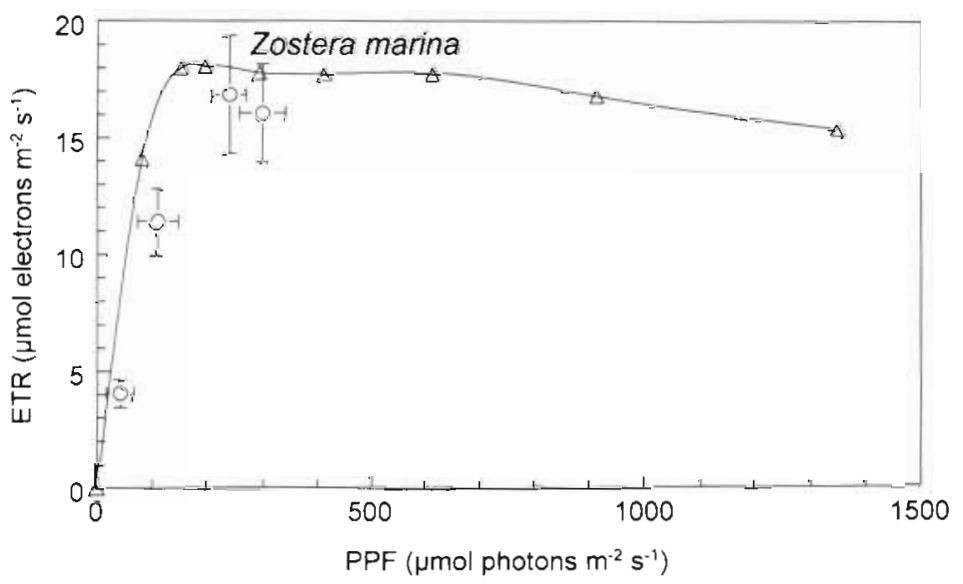

Fig. 9. Rapid light curve of photosynthetic electron transport rates (ETR) versus incident photosynthetic photon flux (PPF) measured in the field at noon-time $(\Delta)$, and average $(n=20$ to 30$)$ in situ point measurements of ETR $(0), \pm S D$, taken at (from left to right) 09:00,10:30, 12:00 and 13:30 h, for an air-exposed intertidal Zostera marina population at a temperature of $7^{\circ} \mathrm{C}$

Vol 2, Scientific discussions from an international workshop. Faculty of Science, University of Western Australia Beer S, Ilan M (1998) In situ measurements of photosynthetic irradiance responses in two marine Red Sea sponges growing under dim light conditions. Mar Biol 131:613-617

Beer S, Ilan M, Eshel A, Weil A, Brickner I (1998) The use of pulse amplitude modulated (PAM) fluorometry for in situ measurements of photosynthesis in two Red Sea Faviid corals. Mar Biol 131:607-612

Beer S, Waisel Y (1979) Some photosynthetic carbon fixation properties in seagrasses. Aquat Bot 7:129-138

Björk M, Weil A, Semesi S, Beer S (1997) The photosynthetic responses of eight seagrass species from Zanzibar to increased inorganic carbon concentrations. Mar Biol 129: $363-366$ 
Dawson SP, Dennison WC (1996) Effects of ultraviolet and photosynthetically active radiation on five seagrass species. Mar Biol 125:629-638

Drew EA (1978) Physiological aspects of primary production in seagrasses. Aquat Bot 7:139-150

Genty B, Briantais JM, Baker NR (1989) The relationship between quantum yield of photosynthetic electron transport and quenching of chlorophyll fluorescence. Biochim Biophys Acta 990:87-92

Krause GH. Weis E (1991) Chlorophyll fluorescence and photosynthesis: the basics. Annu Rev Plant Physiol Plant Mol Biol 42:313-349

Kubler JE, Raven J (1996) Nonequilibrium rates of photosynthesis and respiration under dynamic light supply. J Phycol 32:963-969

Pearcy RW (1990) Sunflecks and photosynthesis in plant canopies. Annu Rev Plant Physiol Plant Mol Biol 41:421-453

Editorial responsibility: Otto Kinne (Editor),

Oldendorf/Luhe, Germany
Schreiber U, Bilger W (1993) Progress in chlorophyll fluorescence research: major developments during the past years in retrospect. In: Dietmar BH, Heidelberg UL, Darmstadt KE, Kadereit JW (eds) Progress in botany. Springer, Berlin, p $151-173$

Schreiber U, Gademan R, Ralph PJ, Larkum AWD (1997) Assessment of photosynthetic performance of Prochloron patella in hospite by chlorophyll fluorescence measurements. Plant Cell Physiol 38:945-951

Sundberg B, Campbell D, Palmquist K (1997) Predicting $\mathrm{CO}_{2}$ gain and photosynthetic light acclimation from fluorescence yield and quenching in cyano-lichens. Planta 201: $138-145$

Wing SR, Patterson MR (1993) Effects of wave-induced lightflecks in the intertidal zone on photosynthesis in the macroalgae Postelsia palmaeformis and Hedophyllum sessile (Phaeophyceae). Mar Biol 116:519-.525

Submitted: May 18, 1998; Accepted: August 11, 1998 Proofs received from author(s): November 2, 1998 